BARHAM, K.A. (1968) Diagnosis of vasa praevia by amnioscopy. Medical Journal of Australia, 2, 398.

Curl, C.W. \& Johnson, W.L. (1968) Vasa praevia: antipartum diagnosis of a case. Obstetrics and Gynecology, 31, 328.
NAFtolin, F. \& Mishell, D.R., JR (1965) Vasa praevia. Report of three cases. Obstetrics and Gynecology, 26, 561.

Paulino, E.H. (1970) Clinical review of vasa praevia in a ten year period. Medical Annals of the District of Columbia, 251, 39.

Postgraduate Medical Journal (November 1974) 50, 725-726.

\title{
Traumatic aortic incompetence following road traffic accident
}

\author{
J. B. IRVING \\ B.SC., M.B., Ch.B., M.R.C.P. \\ Cardiac Department, Western General Hospital, Edinburgh
}

\begin{abstract}
Summary
This case report describes the presentation and treatment of a case of aortic incompetence, resulting from a road traffic accident. The relevant literature is briefly reviewed.

Aortic incompetence due to trauma has been described following non-penetrating chest injuries, such as kicks from horses (Barie, 1881), falls from heights and crushing accidents (Kissane, Koons and Clark, 1948; Levine, Roberts and Morrow, 1962). Despite the frequency of road traffic accidents, there have been no recent reports of traumatic aortic valve damage.
\end{abstract}

\section{Case history}

The patient, a 44-year-old transport manager, was admitted to hospital in September, 1972. He gave a history of increasing breathlessness on exertion over the previous 15 months. For the 2 months before admission he had complained of nocturnal dyspnoea. The symptom of breathlessness as well as episodes of dizziness had dated from May, 1971, when he had been involved in a serious road accident. The nature of the accident was such that, on impact, he had been thrown through the back window of his car, sustaining injuries to the upper thoracic spine and occipital part of the skull. He was unconscious for approximately $10 \mathrm{~min}$ and, on admistion to the casualty department, the principal abnormality was of tenderness, swelling and marked angulation of the thoracic spine. X-rays revealed a compression facture of the 7 th thoracic vertebra. No murmurs were noted and blood pressure was normal. Systolic and early diastolic murmurs were first noted 5 days after admission.

Following discharge the patient noted that he was breathless on climbing stairs and that he suffered quite marked light-headedness on more severe exercise.

In the past history, he had a myocardial infarction in 1968. During that admission only a soft systolic murmur was noted. There were no signs of aortic insufficiency, the heart was of normal size and the electrocardiogram showed normal left ventricular voltages. He was said to have had rheumatic fever at the age of 28, treated at home. Subsequent medical examinations in the Services were satisfactory.

On admission to hospital, he had signs of left ventricular failure and of gross aortic incompetence. Good progress was made on standard therapy but shortly after discharge he was re-admitted in acute pulmonary oedema and subsequently transferred for more specialized investigation.

\section{Examination}

The patient was pale, mildly dyspnoeic with marked Corrigan pulsations in the neck. Jugular venous pressure was elevated and a third sound was audible on auscultation. There was a loud aortic systolic murmur and long aortic diastolic murmur, both radiating to the neck and maximal over the upper left sternal border. Pulse was collapsing, sinus in rhythm, and blood pressure was $180 / 50$. There were bilateral fine crepitations in the chest.

\section{Investigations}

Chest X-ray showed cardiomegaly and pulmonary venous congestion and the ECG showed marked left ventricular hypertrophy. At cardiac catheterization, the left ventricular end diastolic pressure was $15-45 \mathrm{mmHg}$ and a supravalvular angiogram showed severe aortic incompetence. Coronary angiograms were normal except for minor narrowing of the left anterior descending artery. WR was negative. 
Following these investigations and further treatment with digoxin and diuretics, the patient underwent bypass surgery. At operation the aortic valve was replaced with a Bjork prosthetic valve and the operation note stated: 'The ascending aorta was a little enlarged and there was a marked systolic and diastolic thrill in it. The aortic valve was tricuspid. All the cusps were thickened but there was no calcification. The left coronary cusp prolapsed and there appeared to be a tear in it just at the junction between it and the non-coronary cusp. The macroscopic picture did not support either a diagnosis of chronic rheumatic fever or acute traumatic rupture of a cusp'.

The report on the microscopy of the valve stated: 'Section of the leaflets shows dense fibrosis with focal myxomatous areas of collagen degeneration. No diagnostic features of rheumatic fever seen'.

The patient made an uncomplicated postoperative recovery and returned to work after 8 weeks.

\section{Discussion}

The evidence that the aortic incompetence was due to the accident relies on the clinical history. The macroscopic and microscopic appearances were not clearly diagnostic. The alternative explanation, that the valve was diseased from chronic rheumatic fever, is unlikely as the valve was known to be normal in 1968 and the evidence that he had definite rheumatic fever is doubtful. It would be unusual for rheumatic fever to occur at the age of 28 and secondly to cause aortic incompetence as the only lesion.

The delay from the accident to the onset of left ventricular failure is not evidence against this diagnosis. Howard (1928) reviewed 113 cases in the literature. While death was common within days or even hours of the rupture of the valve, some patients lived for 10-15 years after the trauma. The case described by Barie (1881) was symptom-free for several years. Patients may complain of a purring sensation in the chest (Kissane et al., 1948; Leonard, Harvey and Hufnagel, 1955; Sainani and Syatkowski, 1969) following the acute event, but frequently they are preoccupied with other injuries.

Traumatic rupture of aortic valve cusps was probably first described in 1830 by Plenderleath. There have been several reports since then, a frequent cause being a kick from a horse. Since horses were replaced by the motor car there have been no reports of ruptured aortic valves in road traffic accidents, despite the frequency at which they occur. This is surprising and it is possible that damage to valves is overlooked because of the presence of multiple injuries.

\section{Acknowledgments}

I am grateful to Dr K. Murray, Mr P. Walbaum and Dr A. H. Kitchin for permission to publish details of this patient who was under their care.

\section{References}

BARIE, E. (1881) Recherches cliniques et expérimentales sur les ruptures valvulaires du coeur. Revue Médicale, 1, 132.

HowaRD, C.P. (1928) Aortic insufficiency due to rupture by strain of a normal aortic valve. Canadian MedicaP Association Journal, 19, 12.

Kissane, R.W., Koons, R.A. \& Clark, T.E. (1948) Traumatic rupture of aortic valve. American Journal of Medicines 4, 606.

LeONard, J.J., Harvey, W.D. \& HufNagel, C.A. (1955) Rupture of aortic valve. New England Journal of Medicine, 252, 209.

LeVine, R.J., Roberts, W.C. \& Morrow, A.G. (1962) Traumatic aortic regurgitation. American Journal of Cardiology, 10, 752.

Plenderleath (1830) Case of death from rupture of one of the semi-lunar valves of the aorta. London Medical Gazette, vii, 109.

SaINANI, G.S. \& Syatkowski, J. (1969) Rupture of normal aortic valve after physical strain. British Heart Journal, $31,653$. 